\title{
Influence of gas transport mechanisms on the productivity of multi-stage fractured horizontal wells in shale gas reservoirs
}

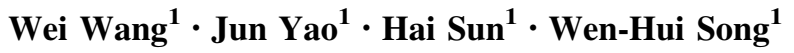

Received: 11 May 2015/Published online: 19 September 2015

(C) The Author(s) 2015. This article is published with open access at Springerlink.com

\begin{abstract}
In order to investigate the influence on shale gas well productivity caused by gas transport in nanometersize pores, a mathematical model of multi-stage fractured horizontal wells in shale gas reservoirs is built, which considers the influence of viscous flow, Knudsen diffusion, surface diffusion, and adsorption layer thickness. A discrete-fracture model is used to simplify the fracture modeling, and a finite element method is applied to solve the model. The numerical simulation results indicate that with a decrease in the intrinsic matrix permeability, Knudsen diffusion and surface diffusion contributions to production become large and cannot be ignored. The existence of an adsorption layer on the nanopore surfaces reduces the effective pore radius and the effective porosity, resulting in low production from fractured horizontal wells. With a decrease in the pore radius, considering the adsorption layer, the production reduction rate increases. When the pore radius is less than $10 \mathrm{~nm}$, because of the combined impacts of Knudsen diffusion, surface diffusion, and adsorption layers, the production of multi-stage fractured horizontal wells increases with a decrease in the pore pressure. When the pore pressure is lower than $30 \mathrm{MPa}$, the rate of production increase becomes larger with a decrease in pore pressure.
\end{abstract}

Keywords Shale gas - Transport mechanisms . Numerical simulation · Fractured horizontal well . Production

Jun Yao

yaojunhdpu@126.com

1 School of Petroleum Engineering, China University of Petroleum, Qingdao 266580, Shandong, China

Edited by Yan-Hua Sun

\section{Introduction}

With the increasing demand for world energy and the improvement of oil and gas exploitation technology, unconventional oil, and gas resources such as coal-bed methane, tight sandstone gas, shale oil, and gas have been paid more and more attention, especially for shale gas which has achieved commercial production (Wu et al. 2013). Shale gas resources in China are competitive with those in America and have great potential for further development (Zhang 2010). In recent years, major breakthroughs have been made in shale gas exploration and production technology in the Sichuan-Chongqing region, where the Sinopec Fuling shale gas field has already been put into commercial production (Yang 2014). The main storage space in shales is nanopores (Zou 2011), shale gas reservoirs in China are deeper, and the formation pressure is higher than those in America (Dong 2012), and gas transport mechanisms are more complicated. Therefore, it is necessary to investigate the influence of gas transport mechanisms on the productivity of fractured horizontal wells in shale gas reservoirs.

Compared with conventional reservoirs, the pore size in shale gas reservoirs is nano-scale (Javadpour et al. 2007; Loucks et al. 2009; Clarkson et al. 2013), which results in low porosity and ultra-low permeability. The matrix porosity generally is lower than 0.1 , and the matrix permeability ranges from 1 nanoDarcy to 1 microDarcy (Wang et al. 2009). The shale formation acts as both the source rock and the reservoir rock, so adsorbed gas and free gas coexist in shale reservoirs (Yao et al. 2013a), where free gas is stored in the matrix pore space, and adsorbed gas can make up to $20 \%-85 \%$ of the total gas reserve (Hill and Nelson 2000). It is different pore sizes and different gas storage patterns in shales that makes the mechanisms of 
shale gas transport in nanopores extremely complicated. These include viscous flow, Knudsen diffusion, and molecular diffusion (which only happens when the gas is multi-component) (Bird et al. 2007). If adsorbed gas exists in porous media, surface diffusion, adsorption, and desorption should also be considered amongst the shale gas transport mechanisms (Ho and Webb 2006; Akkutlu and Fathi 2012).

Because of nano-scale porous media in shale gas reservoirs, the traditional Darcy's law cannot accurately describe the mechanism of gas transport. The existence of nanopores in shale reservoirs makes the gas slippage effect more apparent (Swami et al. 2012). However, the Klinkenberg model only applies to low-pressure gas (Klinkenberg 1941). Based on the model of micro-nano pipes, Beskok and Karniadakis put forward a volumetric flow rate formula with different flow regimes (Beskok and Karniadakis 1999). The Beskok model that describes gas flow in a single tube has been applied to research into tight gas and shale gas flow by Civan et al. in which the Knudsen number is used to describe the transport mechanism that incorporates viscous flow and Knudsen diffusion (Civan 2010; Civan et al. 2010, 2011). Javadpour (2009) considered that Darcy's law and Fick's law can describe gas transport mechanisms in micropores, and Knudsen diffusion is the main gas transport mechanism in nanopores. Thus, the Javadpour model which takes viscous flow and Knudsen diffusion into account in nanopores was established (Javadpour 2009), and used the pore radius to characterize gas transport in nanopores. Yao et al. studied matrix viscous flow, Knudsen diffusion, molecular diffusion, and adsorption and desorption based on the double porosity model and used the finite element method (FEM) for numerical simulation of vertical shale gas well production (Yao et al. 2013a, b).

Because of the nano-scale effect, the thickness of the adsorption layer greatly affects the matrix porosity and permeability (Xiong et al. 2012). Meanwhile, the thickness of the adsorption layer is a function of pressure (SakhaeePour et al. 2011). Due to the existence of concentration gradients, adsorbed gas itself undergoes surface diffusion (Sheng et al. 2014), especially in nano-scale porous media, where surface diffusion is an important transport mechanism. In ultra-tight nano-scale porous media, surface diffusion even dominates the gas transport mechanisms (Sheng et al. 2014; Etminan et al. 2014; Mi et al. 2014; Ren et al. 2015).

Based on previous research, in this paper, we overall consider the shale matrix micro-nano-scale effect, which includes the influence of viscous flow, Knudsen diffusion, surface diffusion, and adsorption layer thickness and build a mathematical model of multi-stage fractured horizontal wells in shale gas reservoirs. Furthermore, the discrete- fracture model (DFM) is used to simplify the fracture description, and the FEM is applied to solve the model. Finally, the influences of different transport mechanisms on shale gas reservoir production are studied, and a parameter sensitivity analysis is used to investigate the change on production and the transport mechanism contribution to well production.

\section{Shale gas transport mechanisms in the reservoir matrix}

Gas transport in shale nanopores consists of several transport mechanisms, as shown in Fig. 1 (Sun et al. 2015). Molecular diffusion is caused by collision between different component gas molecules. For a single gas species, collision between molecules results in viscous flow, and Knudsen diffusion is generated from collision between molecules and the pore walls, while surface diffusion happens when adsorbed gas molecules creep along the pore surface. Considering that there only exists a single-component, methane gas, in the shale gas reservoir and free gas coexists with adsorbed gas in the shale matrix, gas transport mechanisms in the shale matrix is determined by mutual effect of viscous flow, Knudsen diffusion and adsorption layer surface diffusion.

\subsection{Viscous flow}

When the mean-free path of gas molecules is very small compared to the pore diameters, the probability of collisions between molecules is much higher than collisions between molecules and pore walls; thus, single-component gas transport is mainly governed by viscous flow caused by the pressure gradient. Viscous flow can be modeled by Darcy's law (Kast and Hohenthanner 2000):

$N_{\mathrm{v}}=-\frac{\rho_{\mathrm{m}} k_{\infty}}{\mu_{\mathrm{m}}}\left(\nabla p_{\mathrm{m}}\right)$

where $N_{\mathrm{v}}$ is the mass flux of viscous flow, $\mathrm{kg} /\left(\mathrm{m}^{2} \mathrm{~s}\right) ; k_{\infty}$ is the intrinsic permeability of the porous media, $\mathrm{m}^{2} ; p_{\mathrm{m}}$ is the matrix gas pressure, $\mathrm{Pa} ; \rho_{\mathrm{m}}$ is the matrix gas density, $\mathrm{kg}$ / $\mathrm{m}^{3}$; and $\mu_{\mathrm{m}}$ is the matrix gas viscosity, $\mathrm{Pa}$ s.

\subsection{Knudsen diffusion}

When the pore space is so narrow that the mean-free path of gas molecules is very close to the pore diameter, collisions between molecules and pore walls dominate. Knudsen diffusion can be expressed as (Florence et al. 2007)

$N_{\mathrm{k}}=-M_{\mathrm{g}} D_{\mathrm{k}}\left(\nabla C_{\mathrm{m}}\right)$ 


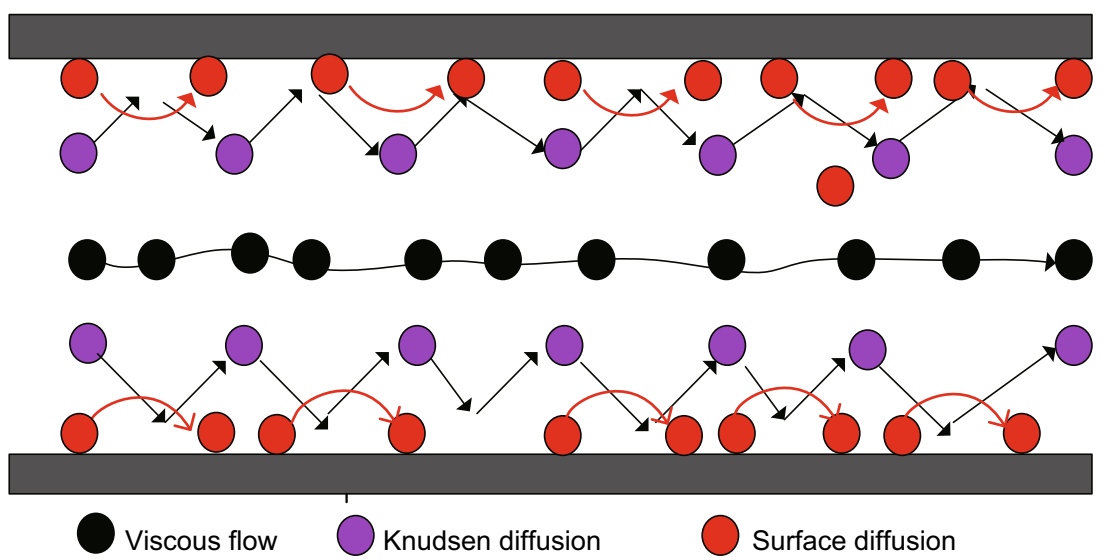

Fig. 1 Single-component gas transport in porous media

$C_{\mathrm{m}}$ can be given by $C_{\mathrm{m}}=\frac{\rho_{\mathrm{m}}}{M_{\mathrm{g}}}=\frac{p_{\mathrm{m}}}{Z R T}$, and $\rho_{\mathrm{m}}$ is obtained by $\rho_{\mathrm{m}}=\frac{p_{\mathrm{m}} M_{\mathrm{g}}}{Z R T}$

$N_{\mathrm{k}}=-\frac{\rho_{\mathrm{m}} D_{\mathrm{k}}\left(\nabla p_{\mathrm{m}}\right)}{p_{\mathrm{m}}}$

$D_{\mathrm{k}}=\frac{4 k_{\infty} c}{2.81708 \sqrt{\frac{k_{\infty}}{\phi_{\mathrm{m}}}}} \sqrt{\frac{\pi R T}{2 M_{\mathrm{g}}}}$,

where $N_{\mathrm{k}}$ is the mass flux of Knudsen diffusion, $\mathrm{kg} /\left(\mathrm{m}^{2} \mathrm{~s}\right)$; $M_{\mathrm{g}}$ is the molecular weight of gas, $\mathrm{kg} / \mathrm{mol} ; D_{\mathrm{k}}$ is the Knudsen diffusivity, $\mathrm{m}^{2} / \mathrm{s} ; C_{\mathrm{m}}$ is the concentration of free gas in the porous media, $\mathrm{mol} / \mathrm{m}^{3} ; Z$ is the gas compressibility factor; $R$ is the ideal gas constant, $8.314 \mathrm{~J} /(\mathrm{mol} \mathrm{K})$; $T$ is the gas reservoir temperature, $\mathrm{K} ; \phi_{\mathrm{m}}$ is the shale matrix porosity; and $c$ is a constant close to 1 . In this paper, we set $c=1$.

\subsection{Adsorption and desorption}

Shale gas adsorbed on the surfaces of nanopores follows the mono-layer Langmuir isotherm adsorption equation (Civan et al. 2011):

$q_{\text {ads }}=\frac{\rho_{\mathrm{s}} M_{\mathrm{g}}}{V_{\mathrm{std}}} \cdot \frac{V_{\mathrm{L}} p_{\mathrm{m}}}{p_{\mathrm{L}}+p_{\mathrm{m}}}$,

where $q_{\text {ads }}$ is the mass of gas adsorbed per solid volume, $\mathrm{kg} / \mathrm{m}^{3} ; \rho_{\mathrm{s}}$ denotes the shale matrix density, $\mathrm{kg} / \mathrm{m}^{3} ; V_{\text {std }}$ is the molar volume of gas at standard temperature $(273.15 \mathrm{~K})$ and pressure $(101,325 \mathrm{~Pa})$, std $\mathrm{m}^{3} / \mathrm{mol} ; V_{\mathrm{L}}$ is the Langmuir gas volume, std $\mathrm{m}^{3} / \mathrm{kg} ; p_{\mathrm{L}}$ is the Langmuir gas pressure, $\mathrm{Pa}$.

The Langmuir isotherm adsorption is based on a monolayer model, and the adsorbed layer makes the effective diameter of the nanopore decrease. The modified effective pore radius caused by the mono-layer adsorption on the pore surface can be written as (Sun et al. 2015)

$r_{\mathrm{eff}}=r-d_{\mathrm{m}} \frac{p_{\mathrm{m}}}{p_{\mathrm{L}}+p_{\mathrm{m}}}$,

where $r_{\text {eff }}$ is the effective pore radius, $\mathrm{m} ; r$ is the pore radius, $\mathrm{m} ; d_{\mathrm{m}}$ is the diameter of a methane molecule, $\mathrm{m}$.

The decrease in the pore diameter leads to a reduction in porosity. Thus, the effective porosity can be expressed as

$\phi_{\mathrm{meff}}=\frac{\phi_{\mathrm{m}} r_{\mathrm{eff}}^{2}}{r^{2}}$

By combining Eqs. (6) and (7), the effective intrinsic permeability that takes the adsorption layer thickness into account can be given by

$k_{\infty \mathrm{eff}}=\frac{\phi_{\mathrm{meff}} r_{\mathrm{eff}}^{2}}{8 \tau}$

where $k_{\infty \text { eff }}$ is the effective intrinsic permeability of the shale matrix, $\mathrm{m}^{2} ; \tau$ is the tortuosity.

\subsection{Surface diffusion}

Surface diffusion only occurs in porous media where the gas is adsorbed onto the pore wall, and can be expressed as $N_{\mathrm{s}}=-M_{\mathrm{g}} D_{\mathrm{s}}\left(\nabla C_{\mathrm{s}}\right)$,

where $N_{\mathrm{s}}$ is the mass flux of surface diffusion, $\mathrm{kg} /\left(\mathrm{m}^{2} \mathrm{~s}\right) ; D_{\mathrm{s}}$ is the surface diffusivity, $\mathrm{m}^{2} / \mathrm{s} ; C_{\mathrm{s}}$ is the concentration of adsorbed gas, $\mathrm{mol} / \mathrm{m}^{3}$. Gas adsorbed on pore surfaces follows the Langmuir isotherm adsorption and can be expressed as (Xiong et al. 2012)

$N_{\mathrm{s}}=-M_{\mathrm{g}} D_{\mathrm{s}} \frac{C_{\mathrm{s} \max } p_{\mathrm{L}}}{\left(p_{\mathrm{m}}+p_{\mathrm{L}}\right)^{2}}\left(1-\frac{r_{\mathrm{eff}}^{2}}{r^{2}}\right)\left(\nabla P_{\mathrm{m}}\right)$, 
where $C_{\mathrm{s}} \max$ is the maximum adsorbent concentration, $\mathrm{mol} / \mathrm{m}^{3}$.

\section{Establishment and solution of the fractured horizontal well mathematical model in shale gas reservoirs}

\subsection{Transport equation for the matrix system}

Mass transport in nano-scale porous media is the concurrent result of viscous flow, Knudsen diffusion, surface diffusion, and gas desorption. The advective-diffusive model (ADM) and dusty gas model (DGM) are generally used to incorporate the coupling mechanisms. Although DGM considers coupling effect between viscous flow and diffusion more comprehensively, the transport equation built by ADM and DGM is the same for a single-component gas (Yao et al. 2013c). Thus, ADM is applied to build the transport equation for the shale matrix:

$N_{\mathrm{t}, \mathrm{m}}=N_{\mathrm{v}}+N_{\mathrm{k}}+N_{\mathrm{s}}=-\frac{\rho_{\mathrm{m}} k_{\mathrm{m}, \mathrm{app}}}{\mu_{\mathrm{m}}}\left(\nabla p_{\mathrm{m}}\right)$

with

$k_{\mathrm{m}, \mathrm{app}}=k_{\infty}\left(1+\frac{b_{\mathrm{m}}}{p_{\mathrm{m}}}\right)+M_{\mathrm{g}} D_{\mathrm{s}} \frac{\mu_{\mathrm{m}}}{\rho_{\mathrm{m}}} \frac{C_{\mathrm{s} \max } p_{\mathrm{L}}}{\left(p_{\mathrm{m}}+p_{\mathrm{L}}\right)^{2}}\left(1-\frac{r_{\mathrm{eff}}^{2}}{r^{2}}\right)$ the reservoir temperature is assumed to stay constant during production. Gas adsorbed on the matrix surface conforms to the Langmuir isotherm adsorption equation. According to the mass conservation law, the continuity equation for a single-porosity matrix system can be obtained:

$\frac{\partial}{\partial t}\left(\rho_{\mathrm{m}} \phi_{\mathrm{m}}+\left(1-\phi_{\mathrm{m}}\right) q_{\mathrm{ads}}\right)+\nabla \cdot N_{\mathrm{t}, \mathrm{m}}=q_{\mathrm{m}} \delta\left(M-M^{\prime}\right)$,

where $N_{\mathrm{t}, \mathrm{m}}$ is the mass flux, $\mathrm{kg} /\left(\mathrm{m}^{2} \mathrm{~s}\right) ; q_{\text {ads }}$ is the mass of gas adsorbed per solid volume, $\mathrm{kg} / \mathrm{m}^{3} ; q_{\mathrm{m}}$ is the source sink term, $\mathrm{kg} / \mathrm{s} ; \delta\left(M-M^{\prime}\right)$ is the delta function which is equal to zero at all points except point $M^{\prime}, \delta\left(M-M^{\prime}\right)=1$.

\subsection{Mathematical model for the matrix system}

Assuming that the pressure is equal on the boundary of hydraulic fractures and the matrix. $\Gamma_{1}$ is the outer boundary of the gas reservoir, $\Gamma_{2}$ is the inner boundary of the production well, and $\Gamma_{3}$ is the boundary between hydraulic fractures and the matrix. In this study, we assume that the outer boundary $\Gamma_{1}$ is sealed, the inner boundary $\Gamma_{2}$ is under a constant pressure, and the pressure is equal across boundary $\Gamma_{3}$. Substituting Eqs. (5) and (11) into Eq. (13), the mathematical model for the single-porosity matrix can be derived:

$$
\left\{\begin{array}{l}
{\left[\gamma \phi_{\mathrm{m}}+\frac{\left(1-\phi_{\mathrm{m}}\right) M_{\mathrm{g}} p_{\mathrm{L}} V_{\mathrm{L}} \rho_{\mathrm{s}}}{V_{\mathrm{std}}\left(p_{\mathrm{L}}+p_{\mathrm{m}}\right)^{2}}\right] \frac{\partial p_{\mathrm{m}}}{\partial t}-\nabla \cdot\left[\gamma\left[\frac{p_{\mathrm{m}} k_{\mathrm{m}, \mathrm{app}}}{\mu_{\mathrm{m}}}\left(\nabla p_{\mathrm{m}}\right)\right]\right]=q_{\mathrm{m}} \delta\left(M-M^{\prime}\right)} \\
\left.p_{\mathrm{m}}(x, y, z, t)\right|_{t=0}=p_{\mathrm{i}} \\
\left.\frac{\partial p_{\mathrm{m}}}{\partial n}\right|_{\Gamma_{1}}=0 \\
\left.p_{\mathrm{m}}\right|_{\Gamma_{2}}=p_{\mathrm{w}} \\
\left.p_{\mathrm{m}}(x, y, z, t)\right|_{\Gamma_{3}}=\left.p_{\mathrm{F}}(x, y, z, t)\right|_{\Gamma_{3}},
\end{array}\right.
$$

$k_{\mathrm{m} \text {,app }}$ is the apparent permeability of the shale matrix; $b_{\mathrm{m}}$ is the Klinkenberg coefficient that considers Knudsen diffusion $b_{\mathrm{m}}=\frac{D_{\mathrm{k}} \mu_{\mathrm{m}}}{k_{\infty}}$.

\subsection{Continuity equation for the matrix system}

We assume that there are no natural fractures in the gas reservoir and the gas is only single-component methane. Adsorbed gas and free gas coexist in the shale matrix, and where $\gamma=\frac{M_{\mathrm{g}}}{Z R T} ; p_{\mathrm{i}}$ is the initial pressure in the gas reservoir, $\mathrm{Pa} ; p_{\mathrm{w}}$ is the wellbore pressure, $\mathrm{Pa}$; and $p_{\mathrm{F}}$ is the pressure in fractures, $\mathrm{Pa}$.

\subsection{Mathematical model for the hydraulic fracture system}

We suppose that only free gas exists in artificial fractures and that the gas obeys Darcy's law within the fracture. The 
pressure is equal across the boundary of hydraulic fractures and the matrix. Thus, the mathematical model for the hydraulic fracture can be represented as

$$
\left\{\begin{array}{l}
\frac{\partial}{\partial t}\left(\rho_{\mathrm{F}} \phi_{\mathrm{F}}\right)+\nabla \cdot\left(\frac{\rho_{\mathrm{F}} k_{\mathrm{F}}}{\mu_{\mathrm{F}}} \nabla p_{\mathrm{F}}\right)=q_{\mathrm{F}} \delta\left(M-M^{\prime}\right) \\
\left.p_{\mathrm{F}}(x, y, z, t)\right|_{t=0}=p_{\mathrm{i}} \\
\left.p_{\mathrm{F}}\right|_{\Gamma_{2}}=p_{\mathrm{w}} \\
\left.p_{\mathrm{m}}(x, y, z, t)\right|_{\Gamma_{3}}=\left.p_{\mathrm{F}}(x, y, z, t)\right|_{\Gamma_{3}}
\end{array},\right.
$$

where $\rho_{\mathrm{F}}$ is the gas density within the fracture, $\mathrm{kg} / \mathrm{m}^{3} ; \phi_{\mathrm{F}}$ is the porosity of the hydraulic fracture, which equals zero when there are no proppants within the fracture; $\mu_{\mathrm{F}}$ is the gas viscosity, $\mathrm{Pa} \mathrm{s} ; k_{\mathrm{F}}$ is the fracture permeability, $\mathrm{m}^{2}$, which can be calculated by the following equations on condition of regular fractures:

$k_{\mathrm{F}}=\frac{\phi_{\mathrm{F}} h_{\mathrm{F}}^{2}}{12}$,

where $h_{\mathrm{F}}$ is the fracture aperture, $\mathrm{m}$.

\subsection{Solution with the finite element method}

The DFM can be used to simplify the description of the hydraulic fracture (Yao et al. 2010; Huang et al. 2011). Three-dimensional fractures are converted into two-dimensional surface elements (as shown in Fig. 2). In order to guarantee equal integral value, the fracture aperture should be multiplied before the surface integral. DFM greatly decreases the number of grids and improves the numerical computation efficiency.

In Eqs. (14) and (15), the DFM is applied to simplify the fracture surface. The FEM is used to solve it, in which tetrahedron elements are used in the matrix, and two-dimensional triangular elements are used in the fracture surface (Li et al. 2010; Yao et al. 2013c). The equations are nonlinear and hard to solve directly; therefore, iteration is used to solve them at an arbitrary time point. The pressure of $n$th time step is applied to obtain the pressure of the

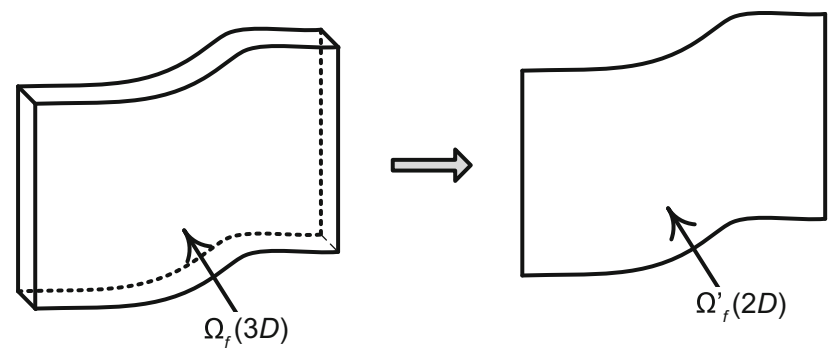

Fig. 2 Schematic diagram of the discrete-fracture model

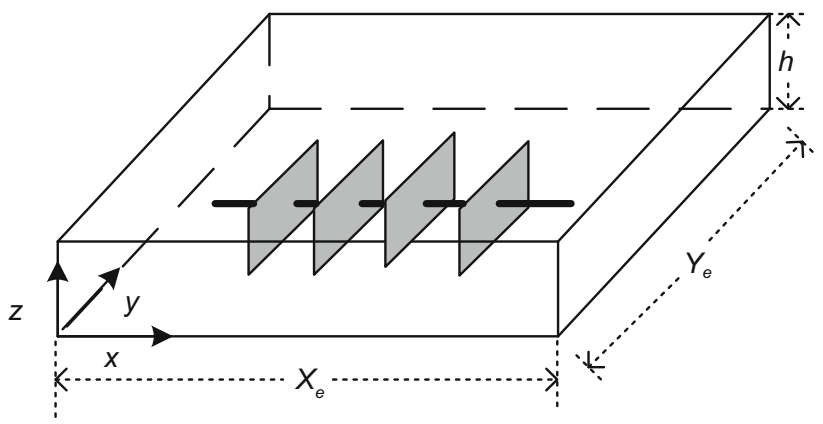

Fig. 3 3D schematic map of the fractured horizontal well

Table 1 Basic data used in the simulation of the multi-staged fractured horizontal well

\begin{tabular}{ll}
\hline Basic parameter & Value \\
\hline Gas reservoir size $X_{\mathrm{e}} \times Y_{\mathrm{e}} \times h, \mathrm{~m}$ & $1500 \times 1500 \times 50$ \\
Initial reservoir pressure, $\mathrm{MPa}$ & 15 \\
Horizontal well length, $\mathrm{m}$ & 800 \\
Pore radius, $\mathrm{nm}$ & $1,5,10,25,50,100$ \\
Wellbore radius, $\mathrm{m}$ & 0.1 \\
Intrinsic matrix permeability, $\mu^{2}$ & $1 \times 10^{-7}$ \\
Matrix porosity & 0.05 \\
Number of fractures & 8 \\
Fracture half-length, $\mathrm{m}$ & 100 \\
Fracture spacing, $\mathrm{m}$ & 100 \\
Fracture aperture, $\mathrm{m}$ & 0.005 \\
Well bottom pressure, $\mathrm{MPa}$ & 4 \\
Gas reservoir temperature, ${ }^{\circ} \mathrm{C}$ & 52 \\
Gas component & Methane \\
Matrix density, $\mathrm{kg} / \mathrm{m}^{3}$ & 2600 \\
Langmuir volume, $\mathrm{m}^{3} / \mathrm{kg}$ & $3 \times 10^{-3}$ \\
Langmuir pressure, $\mathrm{MPa}$ & 6 \\
\end{tabular}

$(n+1)$ th time step. To guarantee algorithm stability, an implicit backward difference method about time is utilized.

\section{Numerical example and analysis of factors affecting production}

In this paper, a multi-stage fractured horizontal well in the middle of a box-shaped sealed reservoir is simulated, with its coordinate ranging from $\left(x_{1}, y_{0}, z_{0}\right)$ to $\left(x_{2}, y_{0}, z_{0}\right)$. Vertical hydraulic fractures are in the shape of rectangles symmetrically distributed around the horizontal well (as shown in Fig. 3). The gas reservoir is penetrated up and down by hydraulic fractures. Meanwhile, the gas reservoir is assumed to be homogeneous, and the influence of gravity is ignored. The basic parameters of the gas reservoir and fractured horizontal well are shown in Table 1. 


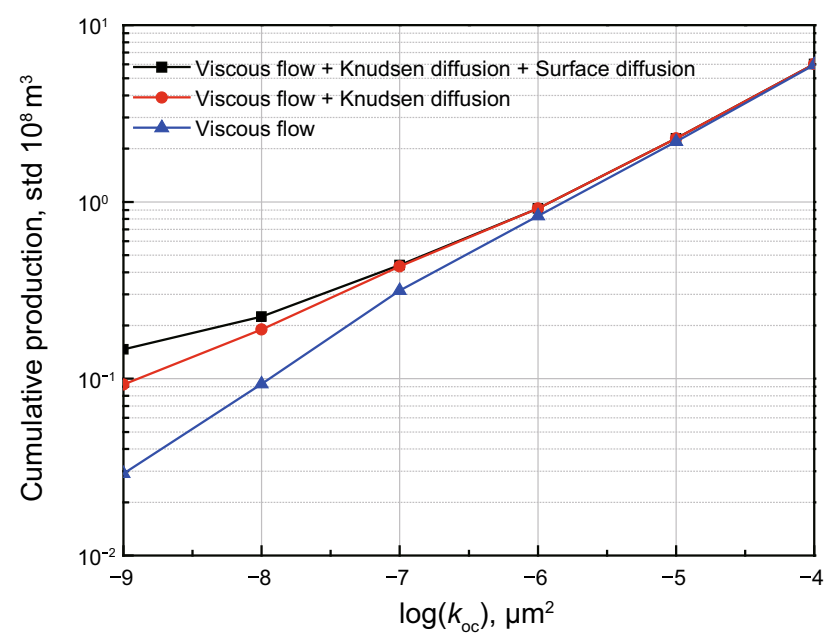

Fig. 4 Cumulative production predicted by different transport models

\subsection{Influence of transport mechanisms}

Because of the nanopores in shale reservoirs, the matrix porosity and permeability are extremely low. Due to different pore sizes in porous media, the intrinsic matrix permeability differs, and thus, the influence of viscous flow, Knudsen diffusion, adsorbed layer, and surface diffusion on transport mechanisms varies substantially. Figure 4 shows simulated cumulative production versus intrinsic permeability under different transport mechanisms over 20 years. As illustrated in Fig. 4, when $k_{\infty}>10^{-5} \mu \mathrm{m}^{2}$, because of the relatively large pore size, gas transport in the porous matrix is dominated by viscous flow, Knudsen diffusion and surface diffusion have little impact on the productivity of fractured horizontal wells and can be ignored. When $10^{-7} \mu \mathrm{m}^{2}<k_{\infty}<10^{-5} \mu \mathrm{m}^{2}$, with a decrease in the pore size, the influence of Knudsen diffusion becomes bigger and gradually affects the productivity of fractured horizontal wells and cannot be ignored, but the influence of the surface diffusion still can be ignored. When $k_{\infty}<10^{-7} \mu \mathrm{m}^{2}$, because of the extremely small pore size, gas transport in a porous matrix is dominated by Knudsen diffusion, which has the biggest contribution to the production of fractured horizontal wells. Meanwhile, the impact of surface diffusion on the production of fractured horizontal wells becomes bigger and thus cannot be ignored.

\subsection{Influence of intrinsic matrix permeability}

For a single-porosity shale gas reservoir, the intrinsic matrix permeability is one of the main factors that affect the productivity of fractured horizontal wells. From Fig. 5, with an increase in the intrinsic matrix permeability, daily gas production and cumulative gas production increase dramatically. With a decrease in the intrinsic matrix permeability, gas transport in porous media is gradually dominated by Knudsen diffusion and surface diffusion, and the impact of viscous flow is reduced, which slows the production decline rate and guarantees long-term stable production.

\subsection{Influence of an adsorption layer}

As shown in Fig. 6, because of the existence of adsorbed gas, the effective pore size and effective porosity decrease. With a decrease in the pore radius, the fractured horizontal
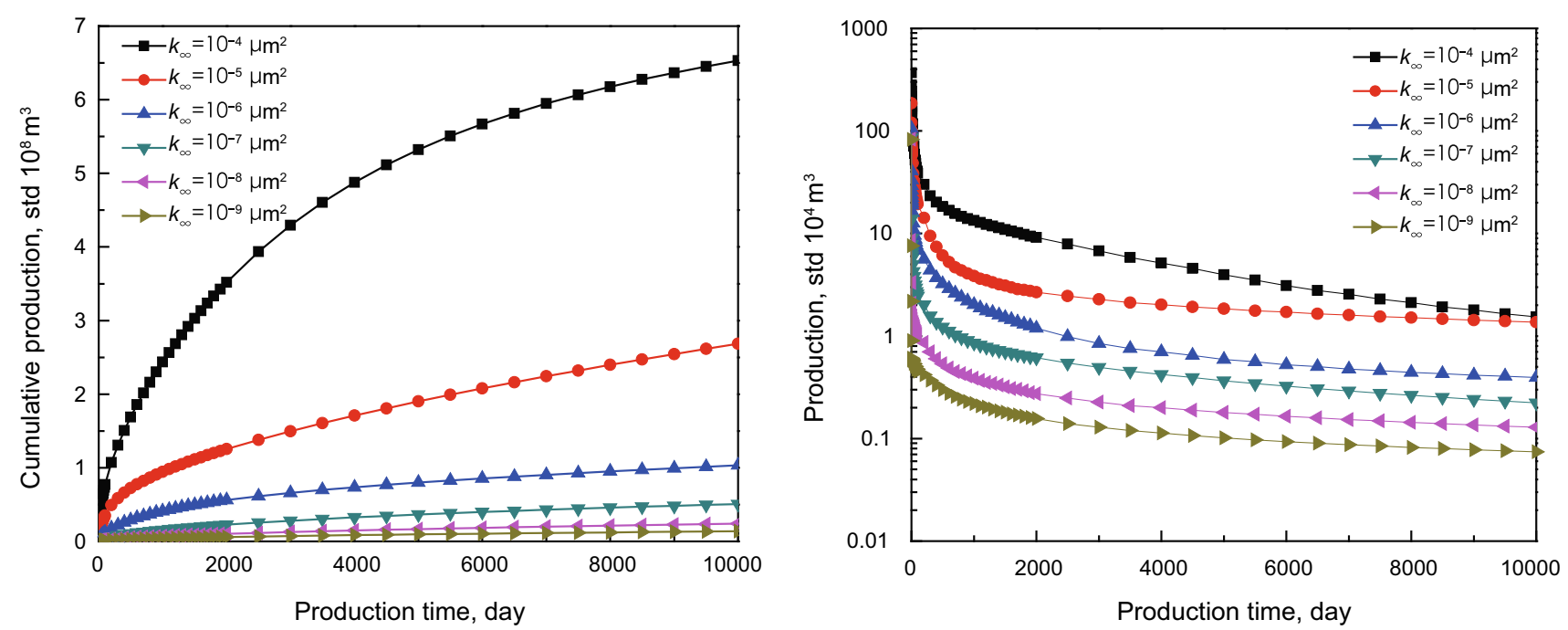

Fig. 5 Effects of intrinsic matrix permeability on production and cumulative production 

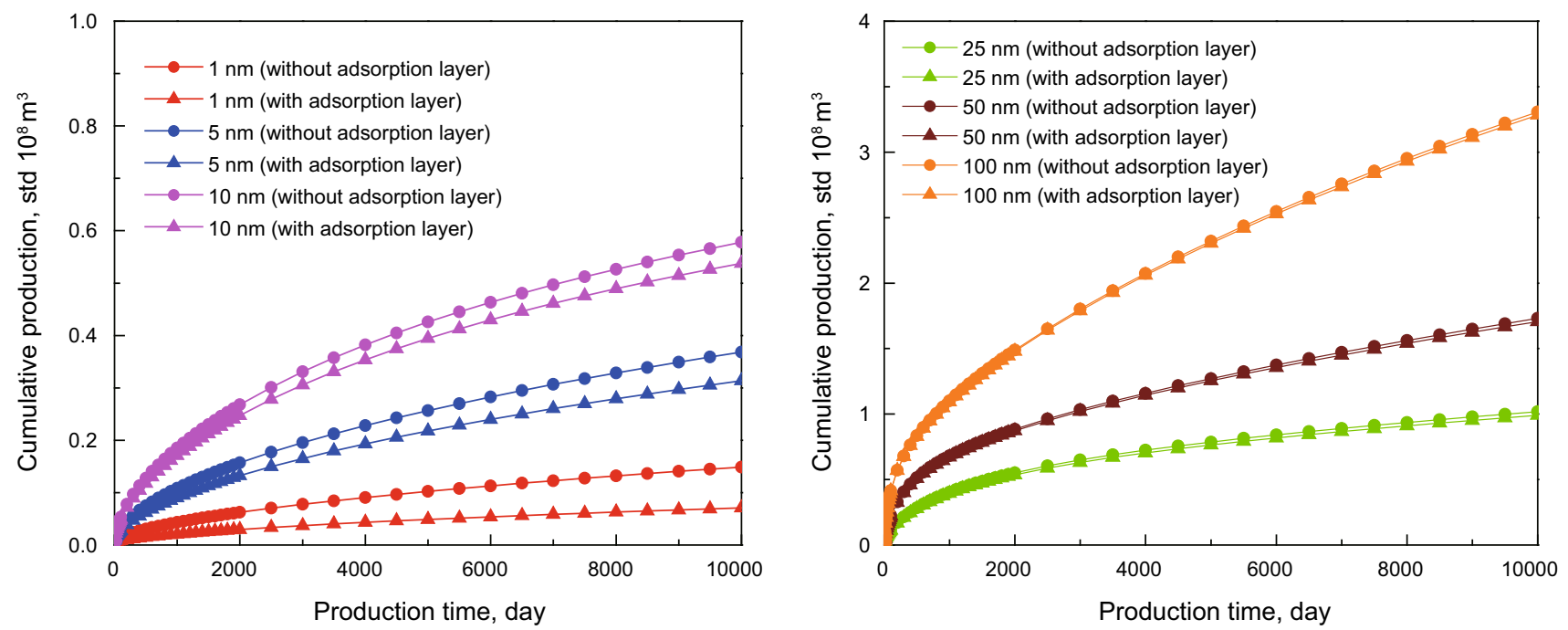

Fig. 6 Impact of the adsorption layer on fractured horizontal well productivity with different pore radii

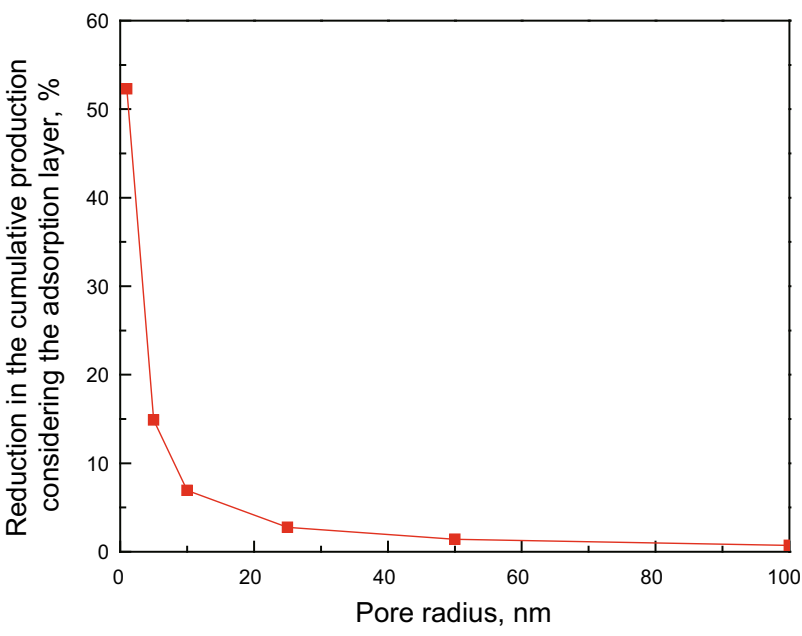

Fig. 7 Impact of adsorption layer on the reduction in the cumulative production under different pore radii

well production gradually diminishes for the same production time. The production that involves the adsorption layer is lower than production to which the adsorption layer does not contribute. Furthermore, with a decrease in the pore radius, the ratio of the adsorption layer thickness divided by the pore radius gradually increases, and the impact of adsorption layer on production becomes bigger.

The reduction in cumulative production considering the adsorption layer is a percentage that defined as the difference of the cumulative production between without and with the adsorption layer divided by the cumulative production without the adsorption layer. As shown in Fig. 7, when $r>10 \mathrm{~nm}$, whether the adsorption layer thickness is considered or not, the production does not change much, with the reduction in cumulative production all below

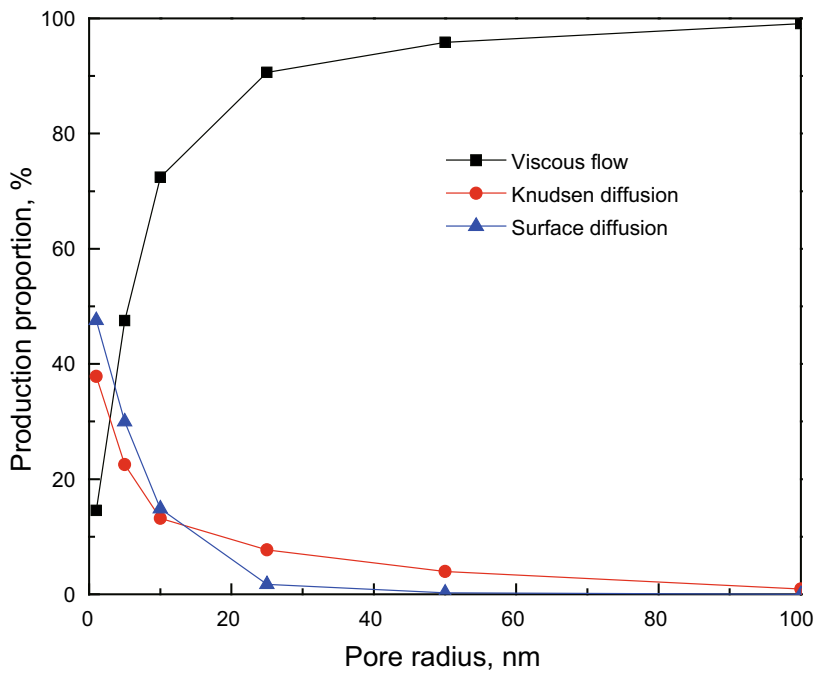

Fig. 8 Contributions to cumulative production by viscous flow, Knudsen diffusion, and surface diffusion under different pore radii

$10 \%$. When $r<10 \mathrm{~nm}$, the influence of the adsorption layer thickness on production cannot be ignored. When $r$ decreases to $1 \mathrm{~nm}$, compared with the cumulative production of 10,000 days without the adsorption layer, the reduction in cumulative production considering the adsorption layer increased up to $52.3 \%$.

As can be seen in Fig. 8, when $r>10 \mathrm{~nm}$, gas transport in a porous medium is dominated by viscous flow. Thus, with a decrease in the pore radius, considering the adsorption layer thickness, the decline rate of the fractured horizontal well production is relatively small. When $r<10 \mathrm{~nm}$, Knudsen diffusion and surface diffusion become the main transport mechanisms. In this condition, with a decrease in the pore radius, considering the 


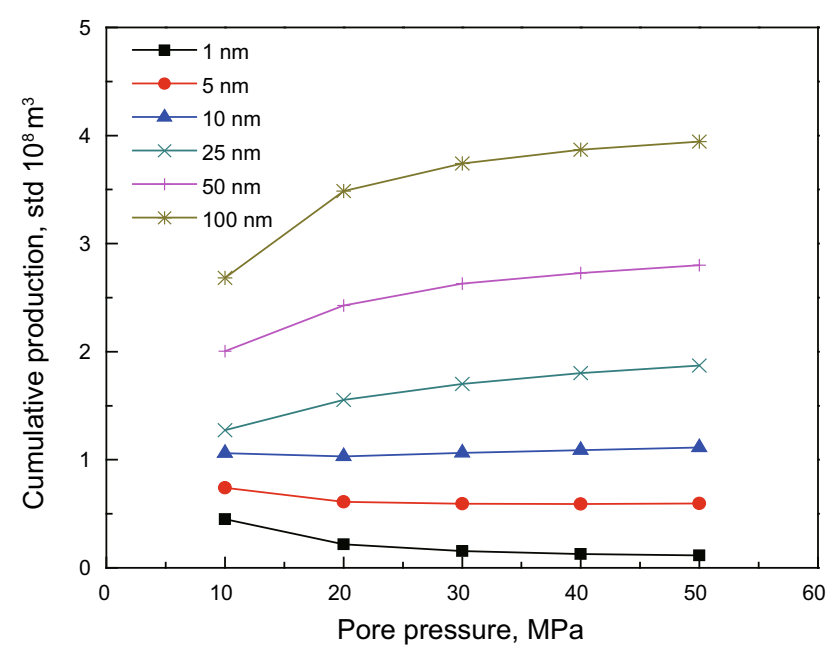

Fig. 9 Cumulative production under different pore pressures and pore radii

adsorption layer thickness, the fractured horizontal well production decrease degree gradually becomes bigger. Therefore, the influence of adsorption layer on production performance and productivity should not be ignored for nano-scale shale gas reservoirs.

\subsection{Influence of gas reservoir pressure}

Figure 9 shows that formation pore pressure dramatically impacts on the gas transport mechanisms in nanopores. When $r>10 \mathrm{~nm}$, gas transport in matrix is dominated by viscous flow while the adsorption layer thickness has little impact on gas transport. Under the same drawdown pressure, with an increase in the formation pore pressure, the

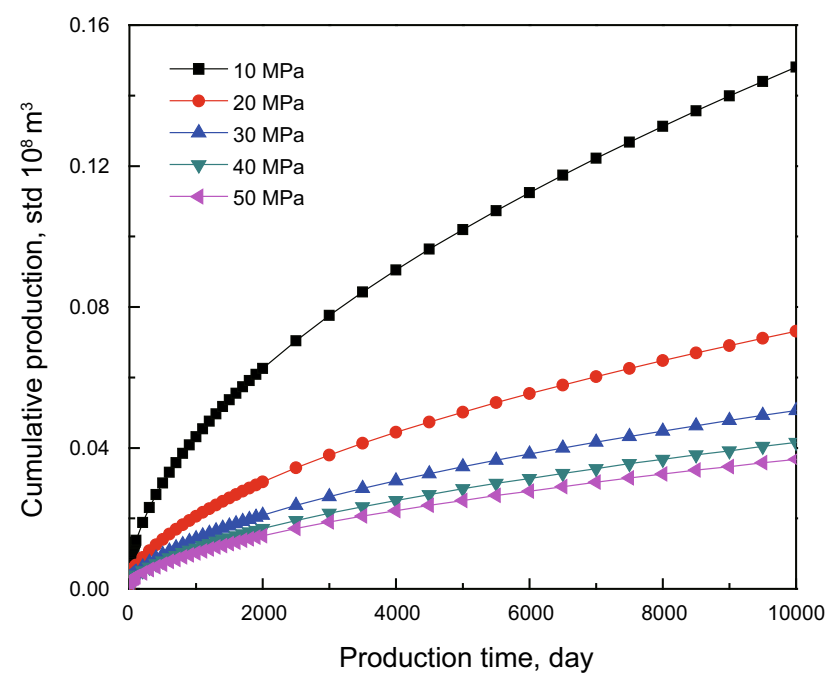

Fig. 10 Cumulative production under different pore pressures at the same drawdown pressure with $r=1 \mathrm{~nm}$ amount of absorbed gas increases correspondingly, and the production of a fractured horizontal well gradually increases. When $r<10 \mathrm{~nm}$, gas transport is dominated by Knudsen diffusion and surface diffusion, and the influence of the adsorption layer thickness on gas transport can no longer be ignored. In this condition, with a decrease in the formation pore pressure, the amount of absorbed gas decreases correspondingly and the thickness of adsorption layer gradually decreases. The increase in well production caused by Knudsen diffusion and surface diffusion exceeds the production loss caused by viscous flow, which makes the production of the fractured horizontal well increase with a decrease in the pore pressure. Surface diffusion varies inversely with the pore pressure, and the variation trend of its contribution to production with pressure change is the opposite to that of viscous flow.

When the pore radius is extremely small (e.g., $1 \mathrm{~nm}$ ), with an increase in the pore pressure, the amount of absorbed gas and the thickness of the adsorption layer increase correspondingly, resulting in a decrease in the effective flow radius and effective porosity. Meanwhile, the cumulative production decreases under the same drawdown pressure (as shown in Fig. 10). When the pore pressure is relatively small, with an increase in the pore pressure, the amount of absorbed gas and the adsorption layer thickness increase significantly and the cumulative production drops dramatically. When the pore pressure is higher than $30 \mathrm{MPa}$, the increasing tendency of the amount of gas and the adsorption layer thickness slow down and tend to constant values. Meanwhile, the effective pore radius and the effective porosity gradually become stable, and the decrease in the cumulative production becomes smaller. The higher the pore pressure is, the smaller the influence of Knudsen diffusion and surface diffusion on production is. When the pore pressure is high enough, the influence of surface diffusion on production is hard to observe and thus can be ignored.

\section{Conclusions}

In this paper, gas transport mechanisms in shale nanopores are established, considering the influence of viscous flow, Knudsen diffusion, surface diffusion, the adsorption layer, and gas desorption. A finite element method is used to investigate the influence of shale gas transport mechanisms on the productivity of the multi-stage fractured horizontal well. The following conclusions can be made.

(1) With Knudsen diffusion and surface diffusion taken into account, the productivity of a multi-stage fractured horizontal well is higher than the production that only considers viscous flow. Furthermore, 
as the intrinsic matrix permeability decreases, the increment of fractured horizontal well-cumulative production involving Knudsen diffusion and surface diffusion increases. Therefore, the influence of Knudsen diffusion and surface diffusion on the production of ultra-low permeability shale gas reservoirs should not be ignored.

(2) The intrinsic matrix permeability dramatically influences the productivity of the multi-stage fractured horizontal well. As the intrinsic matrix permeability becomes smaller, the productivity of multi-stage fractured horizontal wells decreases and the middleand late-period production decline rate slows down. This is because when the intrinsic matrix permeability is smaller than $10^{-5} \mu \mathrm{m}^{2}$, Knudsen diffusion and surface diffusion start to play an increasingly important role in gas transport, which guarantees the stable production of fractured horizontal wells.

(3) The existence of an adsorption layer on the nanopore surface reduces the effective pore radius and effective porosity, which lowers the production of fractured horizontal wells. With a decrease in the pore radius, the production decline becomes bigger. When $r<10 \mathrm{~nm}$, Knudsen diffusion and surface diffusion gradually become the main transport mechanisms. The reduction in cumulative production considering the adsorption layer increases up to $52.3 \%$ when $r$ decreases to $1 \mathrm{~nm}$.

(4) When $r<10 \mathrm{~nm}$, with a decrease in the formation pore pressure, the amount of absorbed gas decreases correspondingly and the thickness of the adsorption layer gradually decreases. With Knudsen diffusion and surface diffusion taken into account, the production of multi-stage fractured horizontal wells increases with a decrease in the pore pressure. When the pore pressure is lower than $30 \mathrm{MPa}$, the increment of cumulative production becomes bigger with a decrease in the pore pressure.

The production time of fractured horizontal wells lasts longer, with lower production decline rate in the middle and late period. This is generally believed to be associated with gas adsorption and desorption. This study found that with a decrease in the formation pore pressure, gas transport in a porous matrix is dominated by Knudsen diffusion and surface diffusion, and the adsorption layer thickness decreases correspondingly, which slows the production decline rate. Therefore, the gas transport in nanopores is also the key factor that influences the production performance of shale gas wells. Gas adsorption and desorption on the matrix pore surfaces together with the gas transport mechanism in nanopores determine production behavior and ultimate recoverable reserves of shale gas multi-stage fractured horizontal wells.

Acknowledgments This work was supported by the National Natural Science Foundation of China (No. 51234007, No. 51490654, No. 51504276, and No. 51504277), Program for Changjiang Scholars and Innovative Research Team in University (IRT1294), the Natural Science Foundation of Shandong Province (ZR2014EL016, ZR2014EEP018), China Postdoctoral Science Foundation (No. 2014M551989 and No. 2015T80762), the Major Programs of Ministry of Education of China (No. 311009), and Introducing Talents of Discipline to Universities (B08028).

Open Access This article is distributed under the terms of the Creative Commons Attribution 4.0 International License (http://crea tivecommons.org/licenses/by/4.0/), which permits unrestricted use, distribution, and reproduction in any medium, provided you give appropriate credit to the original author(s) and the source, provide a link to the Creative Commons license, and indicate if changes were made.

\section{References}

Akkutlu IY, Fathi E. Multiscale gas transport in shales with local Kerogen heterogeneities. SPE J. 2012;17(4):1002-11.

Beskok A, Karniadakis GE. Report: a model for flows in channels, pipes, and ducts at micro and nano scales. Microscale Thermophys Eng. 1999;3(1):43-77.

Bird RB, Stewart WE, Lightfoot EN. Transport phenomena. 2nd ed. New York: John Wiley \& Sons Inc; 2007.

Civan F. Effective correlation of apparent gas permeability in tight porous media. Transp Porous Media. 2010;82(2):375-84.

Civan F, Rai CS, Sondergeld $\mathrm{CH}$. Intrinsic shale permeability determined by pressure-pulse measurements using a multiplemechanism apparent-gas-permeability non-Darcy model. In: SPE annual technical conference and exhibition, 19-22 Sept 2010, Florence, Italy. doi:10.2118/135087-MS.

Civan F, Rai CS, Sondergeld CH. Shale-gas permeability and diffusivity inferred by improved formulation of relevant retention and transport mechanisms. Transp Porous Media. 2011;86(3):925-44.

Clarkson CR, Solano N, Bustin RM, et al. Pore structure characterization of North American shale gas reservoirs using USANS/ SANS, gas adsorption, and mercury intrusion. Fuel. 2013;103:606-16.

Dong DZ, Zou CN, Yang H, et al. Progress and prospects of shale gas exploration and development in China. Acta Pet Sin. 2012;33(A01):107-14 (in Chinese).

Etminan SR, Javadpour F, Maini BB, et al. Measurement of gas storage processes in shale and of the molecular diffusion coefficient in kerogen. Int J Coal Geol. 2014;123:10-9.

Florence FA, Rushing JA, Newsham KE, et al. Improved permeability prediction relations for low permeability sands. In: SPE rocky mountain oil \& gas technology symposium, 16-18 April 2007, Denver, Colorado, USA. doi:10.2118/107954-MS.

Hill DG, Nelson CR. Gas productive fractured shales: an overview and update. Gas Tips. 2000;6(2):4-13.

Ho CK, Webb SW. Gas transport in porous media. The Netherlands: Springer; 2006.

Huang ZQ, Yao J, Wang YY, et al. Numerical simulation on water flooding development of fractured reservoirs in a discretefracture model. Chin J Comput Phys. 2011;28(1):41-9. 
Javadpour F. Nanopores and apparent permeability of gas flow in mudrocks (shales and siltstone). J Can Pet Technol. 2009;48(8): $16-21$.

Javadpour F, Fisher D, Unsworth M. Nanoscale gas flow in shale gas sediments. J Can Pet Technol. 2007;46(10):55-61.

Kast W, Hohenthanner CR. Mass transfer within the gas-phase of porous media. Int J Heat Mass Transf. 2000;43(5):807-23.

Klinkenberg LJ. The permeability of porous media to liquids and gases. Drill Prod Pract. 1941;1:200-13.

Li YJ, Yao J, Huang ZQ, et al. Finite element simulation of heterogeneous reservoir with full permeability tensor. Chin $\mathrm{J}$ Comput Phys. 2010;27(5):692-8 (in Chinese).

Loucks RG, Reed RM, Ruppel SC, et al. Morphology, genesis, and distribution of nanometer-scale pores in siliceous mudstones of the Mississippian Barnett Shale. J Sediment Res. 2009;79(12): 848-61.

Mi LD, Jiang HQ, Li JJ. Investigation of a shale gas numerical simulation method based on discrete fracture network model. Nat Gas Geosci. 2014;25(11):1795-803 (in Chinese).

Ren JJ, Guo P, Guo ZL, et al. A lattice Boltzmann model for simulating gas flow in kerogen pores. Transp Porous Media. 2015;106(2):285-301.

Sakhaee-Pour A, Bryant SL. Gas permeability of shale. In: SPE annual technical conference and exhibition, 30 Oct-2 Nov 2011, Denver, Colorado, USA. doi:10.2118/146944-MS.

Sheng M, Li GS, Huang ZW, et al. Shale gas transient flow model with effects of surface diffusion. Acta Pet Sin. 2014;35(2): 347-52 (in Chinese).

Sun H, Yao J, Fan DY, et al. Gas transport mode criteria in ultra-tight porous media. Int J Heat Mass Transf. 2015;83:192-9.

Swami V, Clarkson C, Settari A. Non-Darcy flow in shale nanopores: do we have a final answer. In: SPE Canadian unconventional resources conference, 30 Oct-1 Nov 2012, Calgary, Alberta, Canada. doi:10.2118/162665-MS.
Wang FP, Reed RM, John A, et al. Pore networks and fluid flow in gas shales. In: SPE annual technical conference and exhibition, 4-7 Oct 2009, New Orleans, Louisiana, USA. doi:10.2118/124253MS.

Wu X, Ren ZY, Wang Y, et al. Situation of world shale gas exploration and development. Resour Ind. 2013;15(5):61-7 (in Chinese).

Xiong X, Devegowda D, Michel GG, et al. A fully-coupled free and adsorptive phase transport model for shale gas reservoirs including non-Darcy flow effects. In: SPE annual technical conference and exhibition, 8-10 Oct 2012, San Antonio, Texas, USA. doi:10.2118/159758-MS.

Yang N. Development status and prospect of shale gas at home and abroad. Pet Petrochem Today. 2014;8:16-21 (in Chinese).

Yao J, Wang ZS, Zhang Y, et al. Numerical simulation method of discrete fracture network for naturally fractured reservoirs. Acta Pet Sin. 2010;31(2):284-8 (in Chinese).

Yao J, Sun H, Fan DY, et al. Numerical simulation of gas transport mechanisms in tight shale gas reservoirs. Pet Sci. 2013a;10(4): 528-37.

Yao J, Sun H, Fan DY, et al. Transport mechanisms and numerical simulation of shale gas reservoirs. J China Univ of Pet (Edit Nat Sci). 2013b;1:91-8 (in Chinese).

Yao J, Sun H, Huang ZQ, et al. Key mechanical problems in the development of shale gas reservoirs. Sci Sin-Phys Mech Astron. 2013c;43(12):1527-47.

Zhang DW. Strategic concepts of accelerating the survey exploration and exploitation of shale gas resources in China. Oil Gas Geol. 2010;31(2):135-9 (in Chinese).

Zou CN, Dong DZ, Yang $\mathrm{H}$, et al. Conditions of shale gas accumulation and exploration practices in China. Nat Gas Ind. 2011;31(12):26-39 (in Chinese). 